\title{
Impact of Polyamines and Mycorrhiza on Chlorophyll Substance of Maize Grown under Cadmium Toxicity
}

\author{
Prasann Kumar ${ }^{1,2 *}$, Purnima ${ }^{1}$, Johnson Yumnam ${ }^{1}$, Mandala Harshavardhan ${ }^{1}$, \\ Panuganti Swaraj Kuamr ${ }^{1}$, Nada Jyoti ${ }^{1}$, Sunil Kumar ${ }^{1}$, Mohit Naik ${ }^{1}$ and \\ Lamneivah Misao ${ }^{1}$ \\ ${ }^{1}$ Department of Agronomy, School of Agriculture, ${ }^{2}$ Division of Research and Development, \\ Lovely Professional University, Jalandhar, Punjab, 144411, India
}

*Corresponding author

A B S T R A C T

\section{Keywords}

Maize (Zea mays L.),

Heavy metals,

Chlorophyll

Article Info

Accepted:

12 September 2018

Available Online:

10 October 2018
An average data of chlorophyll a and chlorophyll $\mathrm{b}$ were recorded at 30,60 and 90 days in the wake of sowing of maize in Rabi season under cadmium tainted soil. For chlorophyll a, the treatment T17 was found to significantly increase by $0.802 \%, 17.50 \%$ and $5.23 \%$ with respect to T12. Similarly, for chlorophyll $\mathrm{b}$, the treatment T17 was found to have significant effect with $10.90 \%, 7.09 \%$ and $8.05 \%$ increase with respect to $\mathrm{T} 12$.

\section{Introduction}

Maize (Zea mays L.) is known as spearhead of crops on account of its higher hereditary yield potential among the grains. In India, around $28 \%$ of maize produced is utilized for nourishment reason, around $11 \%$ as domesticated animals feed, $48 \%$ as poultry feed, $12 \%$ in wet processing industry (for instance starch and oil generation) and $1 \%$ as seed (Abbasi et al., 2015). Heavy metal(s) are across the board toxins of incredible worry as they are non-degradable and along these lines constant. These metals are utilized in different businesses from which effluents are thusly released into the earth. Substantial metals will be metals with a thickness higher than 5 $\mathrm{gcm}^{-3}$. Cadmium is a hazardous substantial metal having thickness $8.642 \mathrm{~g} \mathrm{~cm}^{-3}$ at $200 \mathrm{C}$.

Cadmium (Cd) is an exceptionally harmful follow component and has been positioned seventh among the main 20 lethal components (Pinto et al., 2004). A polyamine is a natural compound having at least two essential amino gatherings $-\mathrm{NH}_{2}$ bunch Low-atomic weight direct polyamines perform basic capacities in every single living cell. 


\section{Materials and Methods}

The present investigation was completed to assess the similarity of polyamines (putrescine) and mycorrhiza in the relief of initiated poisonous impact of cadmium at 30 , 60 and 90 DAS of Rabi maize. The pot estimate for the trial was in the breadth of 30 $\mathrm{cm}$ and $25 \mathrm{~cm}$ in stature with limit with regards to $10 \mathrm{~kg}$ of soil, having a little gap at the base. Chlorophyll a and chlorophyll $b$ perceptions were recorded at 30,60 and 90 days subsequent to sowing with the assistance of standard scale and cautious perception. The chlorophyll content in leaves was estimated by the method of Arnon (1949). The chlorophyll extraction was done in $80 \%$ acetone. Leaves were washed thoroughly and cut into small discs. $100 \mathrm{mg}$ of such leaves were placed in test tubes containing $25 \mathrm{~mL}$ acetone and chlorophyll was extracted. The suspension was centrifuged at $5000 \mathrm{rpm}$ for $5 \mathrm{~min}$ and supernatant was used for measuring chlorophyll content. The absorbance was read at $645 \mathrm{~nm}$ and $663 \mathrm{~nm} .80 \%$ acetone served on blank. The Chlorophyll content was estimated by the formula as given below:

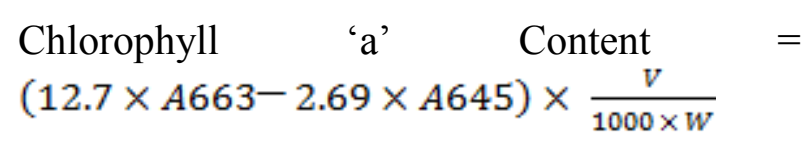

\section{$\begin{array}{lcc}\text { Chlorophyll } \quad \text { ' } b ' \quad \text { content } \\ (22.9 \times A 645-4.68 \times A 663) \times \frac{V}{1000 \times W}\end{array}=$}

\section{Results and Discussion}

Data were recorded at 30, 60 and 90 days after sowing (DAS) (Fig.1). Chlorophyll a content was significantly reduced by $33.70 \%, 30.91 \%$ and $28.53 \%$ when exposed to heavy metal stress (T6) as compared to control (T0) on dates of 30, 60 and 90 DAS of interval. Similarly, when plants were exposed to higher dose of heavy metal (T12) its chlorophyll a content was significantly reduced by $60.65 \%$,
$48.71 \%$ and $38.51 \%$ as compared to control (T0) on the dates of proposed interval. Exogenous application of endomycorrhiza in the soil (T7) showed the mitigation effect by increasing the chlorophyll a content by $0.22 \%$, $5.12 \%$ and $2.03 \%$ as compared to $\mathrm{T} 6$ on the proposed dates of interval. Similarly, when treatment T13 was compared to T12 the chlorophyll a content increased significantly by $1.0 \%, 6.35 \%$ and $1.35 \%$. In comparison to T6, the exogenous application of putrescine (T8) showed the mitigation of chlorophyll a content by $0.108 \%, 13.22 \%$ and $20.85 \%$. The average chlorophyll a content was significantly enhanced as compared to T6 by $0.152 \%, 13.55 \%$ and $19.97 \%$ when treated with higher dose of putrescine (T9) with respect to T8. Similarly, when treatment T14 was compared with T12 the chlorophyll a content increased significantly by $0.076 \%$, $5.93 \%$ and $8.42 \%$ on proposed dates of interval. The average chlorophyll a content was significantly enhanced as compared to T12 with $0.106 \%, 4.615 \%$ and $4.95 \%$ when treated with higher dose of putrescine (T15) with respect to T14. The combination of putrescine and mycorrhiza showed the best mitigation effect by increasing the chlorophyll a content in treatment T10 with $0.446 \%$, $20.73 \%$ and $23.30 \%$ increase with respect to treatment $\mathrm{T} 6$ on proposed dates of interval. When treatment T11 was compared with treatment T6 then significantly chlorophyll a content was increased by $0.584 \%, 21.35 \%$ and $19.7 \%$, respectively. Similar effect was seen in the treatment (T16) with respect to treatment T12. In this treatment the chlorophyll a content was found to increase significantly by the $0.228 \%, 7.17 \%$ and $5.57 \%$, respectively. The treatment $\mathrm{T} 17$ was found to significantly increase $0.802 \%, 17.50 \%$ and $5.23 \%$ with respect to T12. So, the combination of putrescine and mycorrhiza showed the best combination for the mitigation of cadmium toxicity for the chlorophyll a content. Plants exposed to Cd can show many symptoms such 
as chlorosis, leaf roll, and necrosis (Benavides et al., 2005). Chlorosis, leaf roll and stunting are the main and most easily observed toxic symptoms in the presence of excessive amounts of heavy metals. Toxicity may result from the binding of metals to sulphydryl groups in proteins leading to disruption of structure, inhibition of activity and deficiency of essential elements. Chlorophyll contents in mung bean leaf declined with increasing $\mathrm{Cd}$ concentrations which is similar with previous studies (Doganlar and Atmaca, 2011). Cadmium-induced reduction in chl content and chlorosis might be due to the reduction of $\mathrm{Fe}$ in leaves and to the negative effects of $\mathrm{Cd}$ on chl metabolism (Cabala et al., 2011). Degradation of chl due to high activity of chlorophyll-degrading enzyme and/or the inhibition of its biosynthesis by $\mathrm{Cd}$ were proposed to reduce photosynthesis and growth in previous studies (De Andeade and $\mathrm{Da}$ Silveria, 2008). However, chl content increased after Spmpretreatment, compared to $\mathrm{Cd}$ stress only. According to scientist, PAs entering the intact chloroplast protect the photosynthetic apparatus from stress effects. Polyamines stabilize molecular complexes in thylakoid membranes structural constituent of chl and protected chl under osmotic stress (Fig. 1).

Fig.1 Effect of putrescine and mycorrhiza on Chlorophyll "a" content ( $\left.\mathrm{mg} \mathrm{g}^{-1} \mathrm{FW}\right)$ in maize under cadmium stress condition

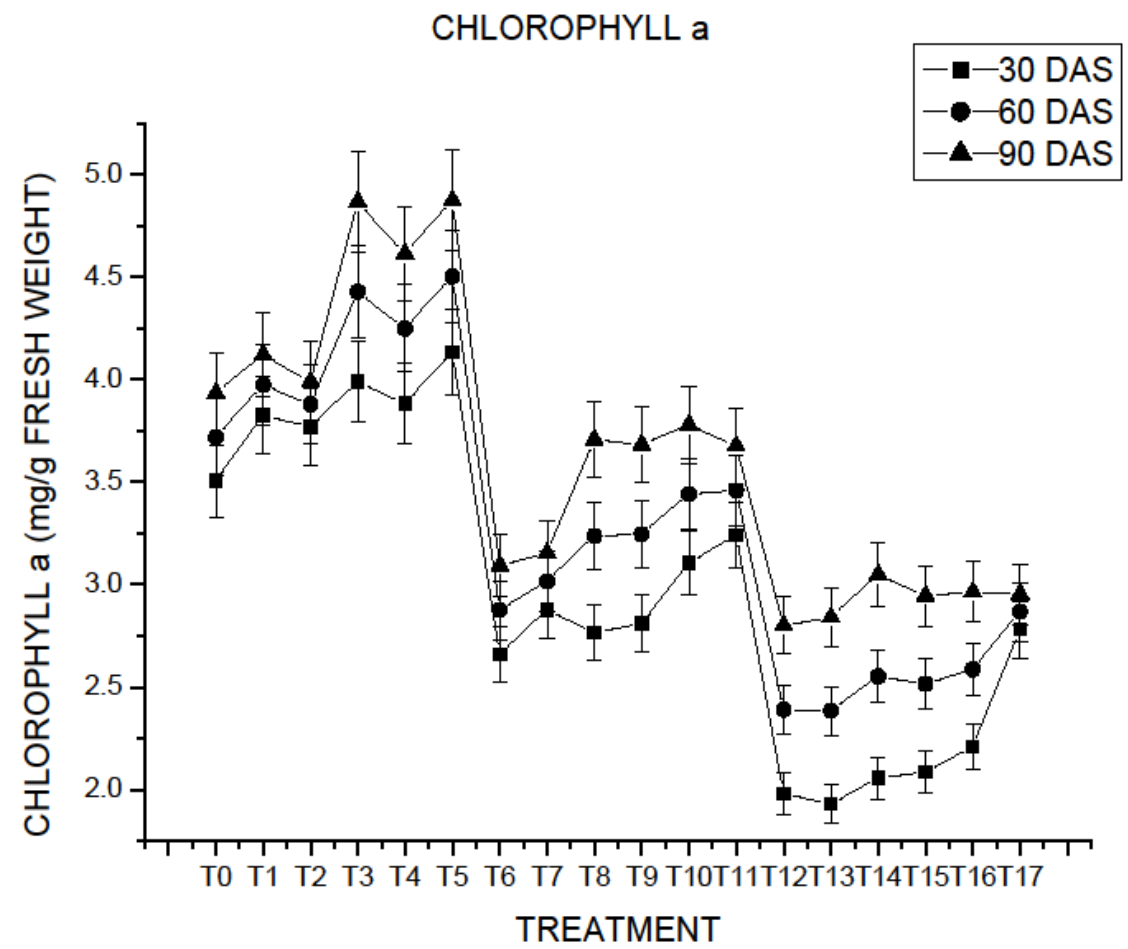

Where, DAS=Days after sowing. Data are in the form of Mean $\pm \mathrm{SEM}$. $\mathrm{S}=$ Significance at $\mathrm{P} \leq 0.05$ and $\mathrm{P} \leq 0.01, \mathrm{NS}=$ Non-Significant at $\mathrm{P} \leq 0.05$ and $\mathrm{P} \leq 0.01$ using Origin 6.1. $\mathrm{T} 0=\mathrm{Control}, \mathrm{T} 1=\mathrm{Control}+\mathrm{Mycorrhiza}, \mathrm{T} 2=\mathrm{Control}+$ $2.5 \mathrm{mM}$ Putrescine, $\mathrm{T} 3=$ Control $+5 \mathrm{mM}$ Putrescine, $\mathrm{T} 4=$ Control $+2.5 \mathrm{mM}$ Putrescine + Mycorrhiza, $\mathrm{T} 5=\mathrm{Control}+$ $5 \mathrm{mM}$ Putrescine + Mycorrhiza, T6 $=0.07 \% \mathrm{Cd}\left(\mathrm{NO}_{3}\right)_{2}, \mathrm{~T} 7=0.07 \% \mathrm{Cd}\left(\mathrm{NO}_{3}\right)_{2}+$ Mycorrhiza, $\mathrm{T} 8=0.07 \% \mathrm{Cd}\left(\mathrm{NO}_{3}\right)_{2}+$ $2.5 \mathrm{mM}$ Putrescine, T9=0.07\% $\mathrm{Cd}\left(\mathrm{NO}_{3}\right)_{2}+5 \mathrm{mM}$ Putrescine, $\mathrm{T} 10=0.07 \% \mathrm{Cd}\left(\mathrm{NO}_{3}\right)_{2}+2.5 \mathrm{mM}$ Putrescine + Mycorrhiza, T11 $=0.07 \% \mathrm{Cd}\left(\mathrm{NO}_{3}\right)_{2}+5 \mathrm{mM}$ Putrescine + Mycorrhiza, T12 $=0.15 \% \mathrm{Cd}\left(\mathrm{NO}_{3}\right)_{2}, \mathrm{~T} 13=0.15 \% \mathrm{Cd}(\mathrm{NO} 3)_{2}$ + Mycorrhiza, T14=0.15\% Cd( $\left(\mathrm{NO}_{3}\right)_{2}+2.5 \mathrm{mM}$ Putrescine, T15=0.15\% Cd( $\left(\mathrm{NO}_{3}\right)_{2}+5 \mathrm{mM}$ Putrescine, T16=0.15\% $\mathrm{Cd}\left(\mathrm{NO}_{3}\right)_{2}+2.5 \mathrm{mM}$ Putrescine + Mycorrhiza, $\mathrm{T} 17=0.15 \% \mathrm{Cd}\left(\mathrm{NO}_{3}\right)_{2}+5 \mathrm{mM}$ Putrescine + Mycorrhiza. 
Fig.2 Effect of putrescine and mycorrhiza on germination chlorophyll " $b$ " content ( $\left.\mathrm{mg} \mathrm{g}^{-1} \mathrm{FW}\right)$ in maize under cadmium stress condition

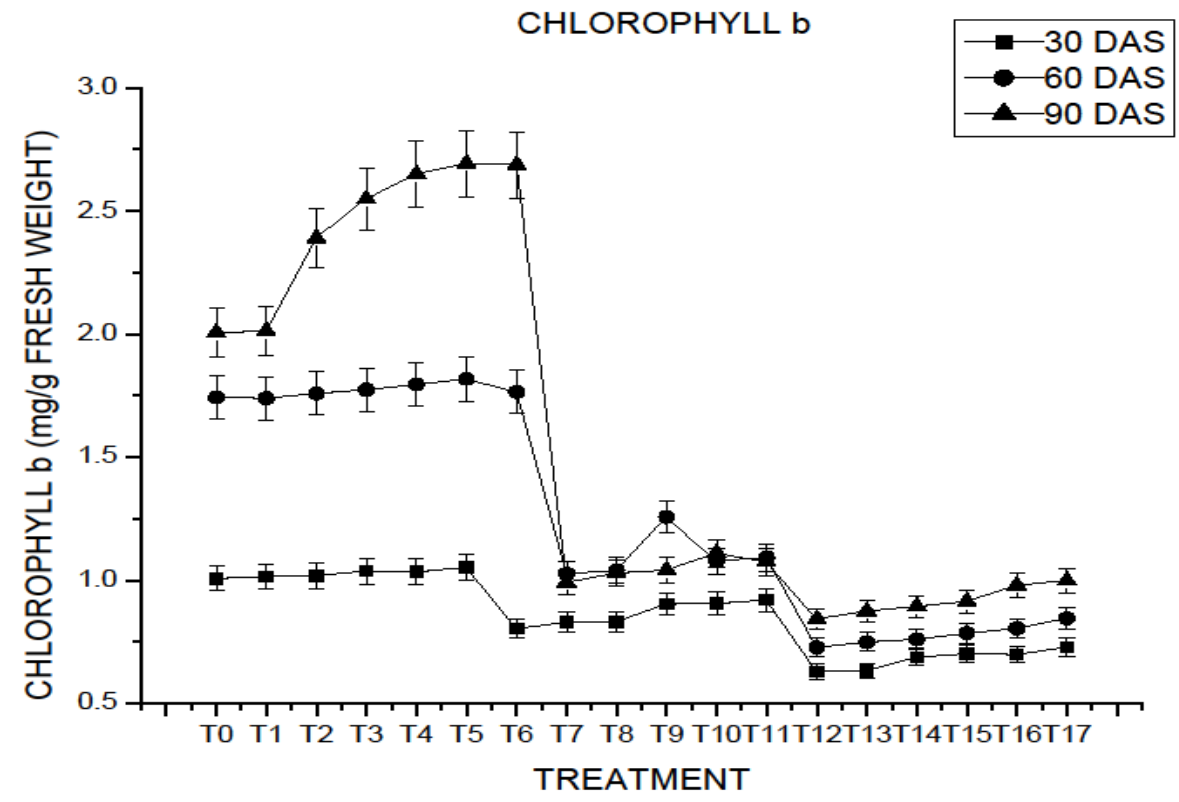

Where, DAS=Days after sowing. Data are in the form of Mean \pm SEM. $S=$ Significance at $\mathrm{P} \leq 0.05$ and $\mathrm{P} \leq 0.01$, NS= Non-Significant at $\mathrm{P} \leq 0.05$ and $\mathrm{P} \leq 0.01$ using Origin 6.1. $\mathrm{T} 0=$ Control, $\mathrm{T} 1=\mathrm{Control}+$ Mycorrhiza, $\mathrm{T} 2=\mathrm{Control}+$ $2.5 \mathrm{mM}$ Putrescine, $\mathrm{T} 3=$ Control $+5 \mathrm{mM}$ Putrescine, $\mathrm{T} 4=$ Control $+2.5 \mathrm{mM}$ Putrescine + Mycorrhiza, $\mathrm{T} 5=$ Control + $5 \mathrm{mM}$ Putrescine + Mycorrhiza, T6=0.07\% Cd(NO$)_{2}, \mathrm{~T} 7=0.07 \% \mathrm{Cd}\left(\mathrm{NO}_{3}\right)_{2}+$ Mycorrhiza, $\mathrm{T} 8=0.07 \% \mathrm{Cd}\left(\mathrm{NO}_{3}\right)_{2}+$ $2.5 \mathrm{mM}$ Putrescine, $\mathrm{T} 9=0.07 \% \mathrm{Cd}\left(\mathrm{NO}_{3}\right)_{2}+5 \mathrm{mM}$ Putrescine, $\mathrm{T} 10=0.07 \% \mathrm{Cd}\left(\mathrm{NO}_{3}\right)_{2}+2.5 \mathrm{mM}$ Putrescine + Mycorrhiza, T11 $=0.07 \% \mathrm{Cd}\left(\mathrm{NO}_{3}\right)_{2}+5 \mathrm{mM}$ Putrescine + Mycorrhiza, $\mathrm{T} 12=0.15 \% \mathrm{Cd}\left(\mathrm{NO}_{3}\right)_{2}, \mathrm{~T} 13=0.15 \% \mathrm{Cd}\left(\mathrm{NO}_{3}\right)_{2}$ + Mycorrhiza, T14 $=0.15 \% \mathrm{Cd}\left(\mathrm{NO}_{3}\right)_{2}+2.5 \mathrm{mM}$ Putrescine, $\mathrm{T} 15=0.15 \% \mathrm{Cd}\left(\mathrm{NO}_{3}\right)_{2}+5 \mathrm{mM}$ Putrescine, $\mathrm{T} 16=0.15 \%$ $\mathrm{Cd}\left(\mathrm{NO}_{3}\right)_{2}+2.5 \mathrm{mM}$ Putrescine + Mycorrhiza, $\mathrm{T} 17=0.15 \% \mathrm{Cd}\left(\mathrm{NO}_{3}\right)_{2}+5 \mathrm{mM}$ Putrescine + Mycorrhiza

Chlorophyll b content was significantly reduced by $22.13 \%, 58.86 \%$ and $67.97 \%$ when exposed to heavy metal stress (T6) as compared to control (T0) on dates of 30, 60 and 90 DAS of interval (Fig. 2). Similarly, when plant was exposed to higher dose of heavy metal (T12) then its chlorophyll b content was significantly reduced by $41.22 \%, 61.09 \%$ and $60.07 \%$ as compared to control (T0) on the dates of proposed interval. Exogenous application of endomycorrhiza in the soil (T7) showed mitigation effect by increasing the chlorophyll $b$ content by $2.72 \%, 15.75 \%$ and $15.65 \%$ as compared to $\mathrm{T} 6$ on the proposed dates of interval. Similarly, when treatment T13 was compared to $\mathrm{T} 12$ the chlorophyll $\mathrm{b}$ content was found to increase significantly by $0.21 \%, 1.32 \%$ and $1.60 \%$ on proposed dates of interval. In comparison to $\mathrm{T} 6$, the exogenous application of putrescine (T8) showed mitigation of chlorophyll b content with $2.94 \%, 16.59 \%$ and $17.66 \%$ increase on proposed dates of interval. The average chlorophyll $b$ content was significantly enhanced as compared to T6 by $10.79 \%, 29.58 \%$ and $18.23 \%$ when treated with higher dose of putrescine (T9) with respect to T8. Similarly, when treatment T14 was compared with T12 the chlorophyll b content increased significantly by $6.32 \%, 2.04 \%$ and $2.63 \%$ on proposed dates of interval. The average chlorophyll b content was significantly enhanced as compared to T12 by $7.96 \%, 3.48 \%$ and $3.66 \%$ when treated with higher dose of putrescine (T15) with respect to T14. The combination of putrescine and mycorrhiza showed the best mitigation effect by increasing the chlorophyll b content in treatment $\mathrm{T} 10$ by $11.12 \%, 18.88 \%$ and $21.79 \%$ with respect to 
treatment T6 on proposed dates of interval. When treatment T11 was compared with treatment $\mathrm{T} 6$ then chlorophyll b content increased significantly by $12.64 \%, 19.78 \%$ and $19.98 \%$ respectively. Similar effect was seen in the treatment (T16) with respect to treatment $\mathrm{T} 12$. In this treatment, the chlorophyll $\mathrm{b}$ content was increased by the $7.63 \%, 4.63 \%$ and $7.07 \%$ respectively. The treatment T17 was found to have significant effect with $10.90 \%, 7.09 \%$ and $8.05 \%$ increase with respect to $\mathrm{T} 12$. So, the combination of putrescine and mycorrhiza showed the best combination for the mitigation of cadmium toxicity for the chlorophyll $b$ content. Sandalio et al., (2001) reported that the chloroplasts, the major component of photosynthetic organ, are highly sensitive to damage exposed to $\mathrm{Cd}$ toxicity. Curbot et al., (2004) observed that the two wheat varieties to which $\mathrm{Cd}$ and $\mathrm{Pb}$ were applied, total chlorophyll decreased. Cho and Kim (2003) noticed that cadmium has a great mobility in soil as compared with other metals, and easily taken up by roots and is translocated to different plant parts. Singh et al., (2003) showed that both growth and photo synthetic pigments affected by the presence of heavy metals.

The decrease in chlorophyll $\mathrm{a}$ and $\mathrm{b}$ content were noticed in both the higher doses of heavy metal treatments $\left(0.07 \% \mathrm{Cd}\left(\mathrm{NO}_{3}\right)_{2}\right)$ and $(0.15 \%$ $\left.\mathrm{Cd}\left(\mathrm{NO}_{3}\right)_{2}\right)$ and the significant increase was noticed in the treatment of putrescine and mycorrhiza.

\section{References}

Abbasi GH, Akhtar J, Malik W, Ali S, Chen $\mathrm{ZH}$, Zhang G. Morpho-physiological and micrographic characterization of maize hybrids under $\mathrm{NaCl}$ and $\mathrm{Cd}$ stress. Plant growth Regulation, 2015; 75(1): 115.

Benavides, M. P., Gallego, S. M. and Tomaro, M. L. (2005). Cadmium toxicity in plants. Brazilian Journal of Plant Physiology, 17(1), 21-34.

Cabala, R., El Zohri, M. and Frank, H. (2011). Accumulation and translocation of $\mathrm{Cd}$ metal and Cd-induced production of glutathione and phytochelatins in Viciafaba L. Acta Physiologiae Plantarum, 33(4), 1239-1248.

Courbot, M., Diez, L., Ruotolo, R., Chalot, M. and Leroy, P. (2004). Cadmiumresponsive thiols in the ectomycorrhizal fungus Paxillus involutus. Applied and Environmental Microbiology,70(12), 7413-7417.

De Andrade, S. A. and da Silveira, A. P. (2008). Mycorrhiza influence on maize development under $\mathrm{Cd}$ stress and $\mathrm{P}$ supply. Brazilian Journal of Plant Physiology, 20(1), 39-50.

Doganlar, Z. B. and Atmaca, M. (2011). Influence of airborne pollution on $\mathrm{Cd}, \mathrm{Zn}$, $\mathrm{Pb}, \mathrm{Cu}$, and $\mathrm{Al}$ accumulation and physiological parameters of plant leaves in Antakya (Turkey). Water, Air, and Soil Pollution, 214(1-4), 509-523.

Pinto AP, Mota AM, Devarennes A, Pinto FC. Influence of organic matter on the uptake of cadmium, Zinc, copper and iron by sorghum plants. Science of Total Environment, 2004; 326: 239-247.

Singh, P.K. and Tewari, R.K. (2003). Effects of heavy metals on plant growth and photosynthetic activity. Journal of Environmental Biology, 24(1), 107-112.

\section{How to cite this article:}

Prasann Kumar, Purnima, Johnson Yumnam, Mandala Harshavardhan, Panuganti Swaraj Kuamr, Nada Jyoti, Sunil Kumar, Mohit Naik and Lamneivah Misao. 2018. Impact of Polyamines and Mycorrhiza on Chlorophyll Substance of Maize Grown under Cadmium Toxicity. Int.J.Curr.Microbiol.App.Sci. 7(10): 1635-1639. doi: https://doi.org/10.20546/ijcmas.2018.710.185 